\title{
Spaanse vreemde woorden in het Nederlands: Periode 2000-2013. Aanvullingen op de Dikke Van Dale
}

\author{
Francisco Sánchez Romero \\ Universidad de Sevilla \\ fsromero@us.es \\ https://dx.doi.org/10.12795/futhark.2014.19.14
}

\begin{abstract}
The purpose of this research is to look into the recent influence of Spanish, both peninsular and from the centre and south of America, (approximately 400 million native speakers altogether) on Dutch (23 million). Spanish foreign words will be analyzed according to the European historical-cultural method, this is, they will be dealt with within a historical frame (in this case from the year 2000). By creating a corpus of Spanish foreign words, I will try to clarify which are the most influential semantic fields on Dutch nowadays. From this division into semantic fields, it will be possible to see what kind of vocabulary has been influential and which has been the degree of contact during the first thirteen years of 21st century.
\end{abstract}

Keywords: Etymology, Foreign words, Spanish-Dutch, Dikke Van Dale.

Samenvatting: In dit onderzoek wordt beoogd inzicht te verkrijgen in de recente invloed van de Spaanse taal, zowel van Spanje als van Centraalen Zuid-Amerika (met ongeveer 400 miljoen moedertaalsprekers in totaal), op het Nederlands (23 miljoen). Spaanse vreemde woorden en leenvertalingen zullen volgens de Europese cultuurhistorische methode worden geanalyseerd, door ze telkens binnen een historisch kader te plaatsen (in dit geval vanaf het jaar 2000). Met de samenstelling van een lexicaal corpus van Spaanse vreemde woorden wordt geprobeerd 
duidelijk te maken welke semantische velden momenteel het meest op het Nederlands van invloed zijn. Op basis van de indeling in semantische velden zal het mogelijk zijn te zien wat voor vocabulaire invloed heeft gehad en wat de mate van contact is geweest gedurende de eerste dertien jaar van de 2le ceuw.

Trefwoorden: Etymologie, Vreemde woorden, Spaans-Nederlands, Dikke Van Dale

\section{OVERZICHT}

Sinds het eind van de $20^{\circ}$ eeuw tot heden speelt enerzijds de etymologe Nicoline van der Sijs een belangrijke rol in de studie naar de invloed van buitenlandse woorden in de Nederlandse taal. Als we kort op het werk van Nicoline van der Sijs ingaan, dan zien we dat Spaanse leenwoorden in het Nederlands slechts tot de $20^{e}$ eeuw zijn bestudeerd.

In Leenzoordenboek: de inoloed van andere talen op het Nederlands (Sijs 1996) $^{1}$, wijdt ze een paragraaf aan de analyse van Spaanse leenwoorden die zij chronologisch tot het jaar 1995 indeelt. In haar tweede etymologische werk, Geleend en Uitgeleend (Sijs 1998: 99-105), analyseert ze zeven Spaanse leenwoorden in het Nederlands [sinjoor, pieremachochel, olipodrigo, parlesanten, armada, commando, majoor] en twee etyma andersom [pichelingue, gaznápiro]. Deze zijn terug te voeren tot de periode van de Tachtigjarige Oorlog. In het derde werk, Chronologisch woordenboek (Sijs 2001), het aantal leenwoorden en leenvertalingen bedraagt 169 . Noch in de paragraaf over de invloed van de Spaanse taal, noch in het bijgesloten register met alle woorden die uit andere talen zijn ontleend, zijn vreemde woorden uit de $21 \mathrm{e}$ eeuw opgenomen.

Meteen daarna legde Nicoline van der Sijs zich toe op de publicatie van werk in de omgekeerde richting, dat is, de bijdrage van het Nederlandse vocabulaire aan andere talen. Zo publiceerde ze in de eerste plaats het Klein Uitleenwoordenboek (Sijs 2006), waarin ze rond de

${ }^{1}$ Dezelfde inhoud is ook verschenen in Uitgeverij Van Dale in 2005 met de titel: Groot Leenwoordenboek. De invloed van andere talen op het Nederlands. 
200 Nederlandse leenwoorden in verschillende talen analyseert. Dit boek is een inleiding op haar latere werk Nederlandse woorden wereldwijd (Sijs 2010), waarin 17.560 Nederlandse leenwoorden worden behandeld die op 138 talen van invloed zijn geweest. In het Spaans is dit een totaal van precies 102 leenwoorden (dit zijn de gevonden leenwoorden in alle geanalyseerde periodes bij elkaar opgeteld), waarvan er 36 direct zijn en 66 indirect. In mijn onderzoek zal ik de indirecte vreemde woorden niet analyseren, omdat ze geen informatie over directe relaties verschaffen.

Anderzijds zien we de taalhistoricus en journalist Ewoud Sanders die, uit zijn talrijke publicaties, in de volgende werken vreemde woorden uit de $21^{\mathrm{e}}$ eeuw behandelt:

- De taal van het jaar (2000): Nieuwe woorden en uitdrukkingen, editie 2001 (Amsterdam / Antwerpen: L.J. Veen 2001). Vermeldt geen enkel woord uit het Spaans afkomstig.

- De taal van het jaar. Tweehonderdvijftig woorden die het aanzien van 2001 bepaalden (Uitgeverij L.J. Veen Amsterdam / Antwerpen 2002). Vermeldt het woord propper 2001, p. 52. Woord dat in Spanje is ontstaan, maar geen etymologische herkomst heeft in de Spaanse taal. Vindt zijn oorsprong in de Nederlandse infinitief proppen.

- De taal van het jaar: de nieuwe woorden en uitdrukkingen van 2002 (Amsterdam / Rotterdam: Prometheus / NRC Handelsblad 2003). Vermeldt twee woorden bolita(slikker), ketchupdans, p. 43.

- De taal van het jaar. De nieuwe woorden en uitdrukkingen van 2003 (Amsterdam / Rotterdam: Prometheus 2004). Vermeldt geen enkel woord uit het Spaans afkomstig.

- Woorden met een verhaal (Amsterdam: Prometheus 2004). Vermeldt geen enkel woord uit het Spaans afkomstig.

- Allemaal woorden (Amsterdam: Prometheus 2005). Vermeldt het woord Pipa 'pistool' 2004. 
- Kolsteren/ Ewoud Sanders, Vreemde Woorden. Prisma Woordenboek, 24te druk 2008. Alleen caramba wordt als eenentwintigste-eeuws woord gevonden.

- Van asotaks tot zedenpleger. Tien jaar nieuwe woorden (NRC Boeken 2009). Vermeldt woorden als bolita(slikker) 2002, ketchupdans 2002, propper 2001. In het kort: dit werk is een samenvatting van zijn eerdere onderzoeken.

\section{METHODOLOGIE}

Om de studie naar Spaanse vreemde woorden in de Nederlandse taal gedurende de jaren 2000-2013 en de daaropvolgende indeling in semantische velden uit te voeren, dien ik uit te gaan van een lexicaal corpus dat alle etyma weergeeft. Het onderzoek beperkt zich tot de etymologische bronnen die in Nederland en in Vlaanderen als de meest prestigieuze worden beschouwd:

a) Elektronisch Groot Woordenboek der Nederlandse Taal. Van Dale. Versie 14.9 (Van Dale 2013). ${ }^{2}$

b) Groot Woordenboek der Nederlandse Taal op CD-ROM. (Dikke Van Dale 13 de druk) Plus versie 1.0. (Van Dale 2000).

c) Groot Woordenboek der Nederlandse Taal op CD-ROM. Versie 14.0. (Van Dale 2005).

d) Cultuurtoeristische Van Dale. Woordenboekgids voor de cultuurtoerist (Van Dale 2007).

e) EWN. Etymologisch woordenboek van het Nederlands (Marlies 2003-2009).

${ }^{2}$ De woorden zullen tot 22 oktober 2013 worden geanalyseerd, datum van lancering van de laatste versie van dit elektronisch woordenboek. 
f) Het woordenboek der Nederlandsche Taal op CD-ROM (iWNT en htpp://gtb.inl.nl).

g) De website http://www.etymologiebank.nl.3

a) Kolsteren/ Ewoud Sanders, Vreemde Woorden. Prisma Woordenboek, ${ }^{24 s t e}$ druk 2008.

b) Ewoud Sanders, Allemaal woorden (Amsterdam: Prometheus 2005).

c) Ewoud Sanders, De taal van het jaar: de nieuwe woorden en uitdrukkingen van 2002 (Amsterdam / Rotterdam: Prometheus / NRC Handelsblad 2003).

d) Ewoud Sanders, Van asotaks tot zedenpleger. Tien jaar nieuwe woorden (NRC Boeken 2009).

Ik zal nu beschrijven welke stappen ik bij de samenstelling van mijn lexicale corpus van 85 woorden heb gevolgd. In de eerste plaats heb ik het Elektronisch Groot Woordenboek der Nederlandse Taal. Dikke Van Dale. Versie 14.9 (Van Dale 2013, 14e editie) doorzocht op het woord 'Spaans'; dit geeft een resultaat van 662 ingangen. 'Amerikaans-Spaans' en 'Argentijns-Spaans' leveren vervolgens een resultaat op van respectievelijk 17 en 3 ingangen.

Vervolgens is nagegaan of deze ingangen zich tevens in het Groot Woordenboek der Nederlandse Taal op CD-ROM. Plus versie 1.0 (Van Dale 2000) bevinden. Aangezien het laatstgenoemde woordenboek alleen ingangen tot het jaar 1999 bevat (Dikke Van Dale, 13e editie), kunnen we de herhalingen uitsluiten en uiteindelijk de Spaanse woorden opnemen die voor de beperkte periode die in dit onderzoek wordt bestudeerd waardevol zijn.

In de derde plaats heb ik nauwkeurig de datering van het eerste schriftelijke voorkomen van deze woorden gepreciseerd, met behulp

3 Verzamelt gedetailleerde informatie over leenwoorden uit 25 etymologische werken in de Nederlandse taal. Deze website wordt geleid door Nicoline van der Sijs en werd opgezet in het jaar 2010. 
van het EWN, het iWNT, en de Etymologiebank. Nicoline van der Sijs vermeldde tapas bijvoorbeeld in 1997 en de Dikke Van Dale in 2005.

In de vierde plaats heb ik de Nederlandse taal afgezocht op Spaanse vreemde woorden aan de hand van de bronnen van Ewoud Sanders. Daarbij heb ik de woorden ketchupdans en pipa gevonden.

Ten vijfde vinden we dat in de Van Dale 14.9 Elektronisch Woordenboek, 42 woorden verschijnen die niet zijn gedateerd: alfiz, alicatado, artesonado, basuco, batucada, burrito, caracara, cava, caramba, cava, churros, crianza, cumbia, el caballero de la triste figura, EFE, ELDR, encierro, garbanzo, GT2, guaganco, Guernica, hoatzin, maquiladora, mocarabe, muralisme, parador, paso, pasco ${ }^{4}$, plateresco, plaza, plaza mayor, PPE-DE, PSE, reserva, serranoham, son, tanguero, tapasbar, tempranillo, tres, TVE, un momento dado.

Na raadpleging van de redactie van uitgeverij Van Dale, werden in het werk getiteld Cultuurtoeristische Van Dale (Van Dale 2007) acht woorden gevonden: alfiz, alicatado, artesonado, mocarabe, paso, pasco ${ }^{5}$, plateresco, plaza mayor. Deze worden in het definitieve lexicale corpus gemarkeerd met twee asterisken: $2007^{\star *}$. We zien dat van de eerste 42 vreemde woorden er 34 nog niet gedateerd zijn. Deze werden in de $14^{\text {e }}$ editie van de Dikke Van Dale uit 2005 in de papieren versie gevonden (editie met CD-ROM). We hebben deze in het definitieve lexicale corpus met één asterisk opgenomen (2005*): basuco (2005*), batucada $\left(2005^{\star}\right)$, burrito $\left(2005^{\star}\right)$, caracara $\left(2005^{*}\right)$, caramba $\left(2005^{*}\right)$, cava $\left(2005^{\star}\right)$, churros $\left(2005^{\star}\right)$, crianza $\left(2005^{\star}\right)$, cumbia $\left(2005^{*}\right)$, EFE $\left(2005^{\star}\right)$, el caballero de la triste figura (2005*, Sijs 2001), ELDR $\left(2005^{\star}\right)$, encierro $\left(2005^{*}\right)$, garbanzo $\left(2005^{\star}\right)$, GT $\left(2005^{*}\right)$, guaguanco $\left(2005^{\star}\right)$, Guernica $\left(2005^{\star}\right)$, hoatzin $\left(2005^{\star}\right)$, maquiladora $\left(2005^{\star}\right)$, muralisme $\left(2005^{\star}\right)$, parador $\left(2005^{\star}\right)$, plaza $\left(2005^{*}\right)$, PPE-DE $\left(2005^{\star}\right)$, PSE $\left(2005^{\star}\right)$, reserva $\left(2005^{\star}\right)$, serranoham $\left(2005^{\star}\right)$, son $\left(2005^{*}\right)$, tanguero $\left(2005^{\star}\right)$, tapasbar $\left(2005^{\star}\right)$, tempranillo $\left(2005^{\star}\right)$, tres $\left(2005^{\star}\right)$, TVE $\left(2005^{*}\right)$, un momento dado $\left(2005^{*}\right)$.

\footnotetext{
${ }^{4}$ Het woord pasco is een tikfout door mij gevonden. Het woord moet natuurlijk 'paseo' zijn met de betekenis 'wandelgang, promenade'. Van Dale uitgeverij zal het onmiddellijk in het bestand aanpassen. In de Dikke Van Dale Online wordt dit al over enkele maanden zichtbaar.

5 Ibíd.
}

Futhark 9 (2014)

ISSN $1886-9300$

Sánchez, Spaanse, 373-391 
Het lexicale corpus van 85 woorden ziet er dan als volgt uit: adios (2012) <esp. adi6s, agouta (2009), alfiz $\left(2007^{\star \star}\right)$, alicatado $\left(2007^{\star *}\right)$, almiqui (2009) <esp. almiquí, artesonado $\left(2007^{\star \star}\right)$, basuco $\left(2005^{*}\right)$, batucada (2005*), bolita/bolletje (2006), bombo (2009), bombonella (2006), botellon (2009) <sp. botellon, bucardo (2006), burrito (2005*), cajón (2008), camino (2012) <esp. Camino de Santiago, caracara $\left(2005^{*}\right)$, caramba $\left(2005^{\star}\right)$, cava $\left(2005^{*}\right)$, cenote (2008), ceviche (2009), chompa (2006), chullo (2010), churros (2005*), charango (2006), conchita (2009), coño (2008), crianza $\left(2005^{*}\right)$, cumbia $\left(2005^{*}\right)$, dogo argentino (2007), duende (2007), el caballero de la triste figura / ridder van de droevige figuur $\left(2005^{\star}\right), \operatorname{EFE}\left(2005^{\star}\right), \operatorname{ELDR}\left(2005^{\star}\right)$, encierro $\left(2005^{\star}\right)$, epazote (2006), escabeche (2013), fajita (2010), garbanzo (2005*), GT $\left(2005^{*}\right)$ <sp. gran turismo, guaguanco $\left(2005^{\star}\right)<$ <p. guaguancó, guanabana (2007), Guernica $\left(2005^{\star}\right)$, hoatzin $\left(2005^{\star}\right)$ <amerikaans-spaans <nahuatl. uatzin, ketchupdans (2002) <sp. Las Kétchup, manchego (2008), maquiladora $\left(2005^{\star}\right)$, melodeon $(2007)<$ sp. melodeón, membrillo (2011), mestizo (2009), mocarabe $\left(2007^{\star \star}\right)<$ sp. mocárabe, mojito (2008), mosquito (2009), muralisme $\left(2005^{\star}\right)$ <esp. muralismo, nacho's $(2013)<$ sp. nachos, paca $(2008)$, paso $\left(2007^{\star \star}\right)$, paseo $\left(2007^{\star \star}\right)$, pata negra (2009), pandeiro (2007), parador $\left(2005^{\star}\right)$, piñata (2009), pipa (2004) < pipa, piperade $(2007)<$ sp. piperrada, plateresco $\left(2007^{\star \star}\right)$, plaza $\left(2005^{\star}\right)$, plaza mayor $\left(2007^{\star \star}\right)$, PPE-DE $\left(2005^{\star}\right)$, PSE $\left(2005^{\star}\right)$, qué (2012), quesadilla (2006), ranchera (2007), reserva (2005*), roner (2013), santeria $(2010)<$ sp. santería, serranoham $\left(2005^{\star}\right)<$ sp. jamón serrano, son $\left(2005^{*}\right)<$ sp. son cubano, tanguero $\left(2005^{*}\right)$, tapa(sbar) $\left(2005^{*}\right)$, tempranillo $\left(2005^{\star}\right)$, tiple $(2007)$, tres $2\left(2005^{\star}\right)$, TVE $\left(2005^{\star}\right)$, un momento dado $\left(2005^{\star}\right)<$ sp. en un momento dado, vihuela (2007).

Naar aanleiding van deze samenstelling van het lexicale corpus rijst dan de vraag of Spaanse woorden op basis van het redactiestandpunt in de Dikke Van Dale worden opgenomen of op basis van andere specifieke criteria. Dit is ook door Ewoud Sanders besproken (2005: 14):

"Zijn er veel mensen die geloven in de mythe dat een woord pas écht
bestaat als het in een woordenboek is opgenomen? Daar lijkt het wel
op. Men heeft het gevoel dat een woord pas echt geaccepteerd is als
het bijvoorbeeld tot de kolommen van de Grote Van Dale is
doorgedrongen. Pas dán heeft een woord (dan wel: een betekenis of 
een uitdrukking) burgerrecht verkregen, pas dan telt het officieel mee... Voor de goede orde: dit artikel is niet bedoeld als kritiek op de Grote Van Dale. Om te voorkomen dat een woordenboek onnodig dik wordt, moet de redactie keuzes maken. Sommige keuzes zijn logisch, over andere kun je twisten."

Als we op de website van Van Dale (http://www.vandale.nl) het onderdeel 'Meestgestelde vragen' raadplegen, dan worden de criteria van uitgeverij Van Dale als volgt toegelicht:

"Wanneer komt een nieuw woord in het woordenboek? Een woord wordt opgenomen in de Grote of Dikke Van Dale als de redactie dat woord gedurende langere tijd (ongeveer drie jaar) regelmatig aantreft in het (schriftelijk) algemeen taalgebruik. Daarvoor doorzoekt de redactie voomamelijk digitale teksten (kranten, tijdschriften, boeken, internet). Deze teksten moeten bedoeld zijn voor een ruimer publiek en ze moeten gemakkelijk toegankelijk zijn voor veel mensen. Dat betekent dat woorden die alleen gebruikt worden in een bepaald vakgebied, in bepaalde kringen of in een bepaalde regio, niet worden opgenomen. Dus als een woord bijvoorbeeld alleen gebruikt wordt door een bepaalde beroepsgroep of alleen bij een bepaalde sportclub of alleen in een klein deel van Nederland of België, dan komt het woord niet in de Dikke Van Dale. Het woord moet algemeen bekend zijn, het moet ingeburgerd zijn. Voor nieuwe uitdrukkingen geldt hetzelfde."

Voorts vinden we Spaanse vreemde woorden die "toegevoegd" en "voorlopig toegevoegd" zijn (vanaf het jaar 2010). Het antwoord op het gebruik van deze twee termen staat op de website van het tijdschrift Onze Taal onder Taalnieuws (27 mei 2013) (https://onzetaal.nl/nieuws/aanvullingen-voor-dikke-van-dale):

"Onderwaterhypotheek, religiestress en chillaxen: dit zijn slechts enkele woorden die zijn toegevoegd aan de (betaalde) onlineversie van de dikke Van Dale. Van Dale gaat de inhoud vaker aanpassen, "om altijd en overal de meest actuele woordenschat beschikbaar te hebben". Tot nu toe werd het woordenboek slechts één keer per jaar aangevuld. De nieuwe woorden worden voorlopig toegevoegd. Als ze langdurig in gebruik blijven - op zijn minst drie jaar - maken ze kans op een volwaardige toevoeging. Voorlopig toegevoegde woorden die niet meer in gebruik blijken te zijn, verdwijnen bij een nieuwe druk van de papieren uitgave." 
Tot op heden treffen we dus 85 Spaanse vreemde woorden in de 21e eeuw, maar zodra de 15e editie op papier uitkomt, zal blijken of er niet enkele verdwijnen. Ook kan het voorkomen dat nieuwe vreemde woorden worden toegevoegd. Op dit moment hebben we 10 'voorlopig toegevoegde' woorden die overeenkomen met de toegevoegde woorden vanaf 2010 tot 2013: adios (2012), camino (2012), chullo (2010), escabeche (2013), fajita (2010), membrillo (2010), nacho's (2013), qué (2012), roner (2013), santeria (2010).

\section{SEMANTISCHE VELDEN}

Wat betreft de historische context kenmerkt de $21^{\text {e }}$ eeuw zich voornamelijk door de overname van Spaanse vreemde woorden in de Nederlandse taal dankzij het toerisme, de muziek en de media. Opvallende vreemde woorden in de laatste groep zijn TVE, de Spaanse publieke omroep, en EFE [genoemd naar de eerste letter van zijn voorganger, het persbureau Fabra (Spaans persbureau)]. Dezelfde media hebben nieuwe woorden geïntroduceerd die uit de Spaanse politiek afkomstig zijn: PPE-DE, PSE. Globalisering, internet en andere nieuwe technologieën zijn van invloed op de snelheid waarmee woorden uitgewisseld worden.

De Nederlandse onderzoekster Van der Sijs heeft reeds een paar van de bekendste Spaanse gerechten opgenomen die zich in de jaren 90 in de rekken van de supermarkten bevinden: "... de schappen van Albert Heijn [liggen] tegenwoordig vol met de exotische gerechten, die tien jaren geleden nog volkomen onbekend waren. Dergelijke namen neem ik wel op, want ze behoren tot het Nederlandse taalgebruik." (Sijs 1996: 67). Van de typische voedingsmiddelen uit Spanje observeren we Spaanse vreemde woorden als chorizo, tortilla, paella, gazpacho. Deze worden inmiddels in elk kookboek met Spaanse recepten in de Nederlandse taal gebezigd. Recenter, in de $21^{\mathrm{e}}$ eeuw, werden de volgende woorden van het Schiereiland in het lexicale corpus overgenomen: conchita, escabeche, manchego, membrillo, pata negra, piperade, churros, garbanzo, serranoham, tapa(sbar), roner [genoemd naar de Spaanse koks Joan Roca en Narcis Caner (voorlopig toegevoegd in 2013) 1 . slowcooker waarin vacuüm getrokken voedsel 
au bain-marie wordt bereid (Van Dale 2013)] Uit Spaans-Amerika zijn van invloed: ceviche, fajita, guanabana, quesadilla, burrito, nacho's. Spaanse dranken hebben meestal betrekking op wijnsoorten: reserva, tempranillo, crianza, cava. Uit Centraal-Amerika wordt slechts één woord ingevoerd: mojito.

In de $20^{\circ}$ eeuw werd een aanzienlijk aantal ontleningen uit het semantisch veld van het stierenvechten gerapporteerd: corrida, espada, banderillero, muleta. Daarnaast verschijnen de vreemde woorden olé en aficionado, die in eerste instantie in een stieren- en dansgerelateerde context zijn ontstaan, maar die zich naar verschillende sporten hebben uitgebreid. $\mathrm{Nu}$ in de $21^{\mathrm{e}}$ eeuw is alleen encierro <esp. los encierros de San Fermin in de Dikke Van Dale opgenomen: "Spaans volksvermaak waarbij stieren door de straten worden gejaagd en het de kunst is zo laat mogelijk opzij te springen" (Van Dale 2013).

Met betrekking tot de Spaanse en Latijns-Amerikaanse muziek merken we op dat dit semantisch veld een opvallende rol speelt in de overdracht van vocabulaire: duende, ketchupdans, vihuela, cajón, ranchera, cumbia, tanguero, son, tiple, tres, batucada, pandeiro, mestizo, melodeon, guaguanco, charango, bombo. Met tal van zomerhits heeft de latinmuziek de hoogste plaatsen op de hitlijsten van verschillende

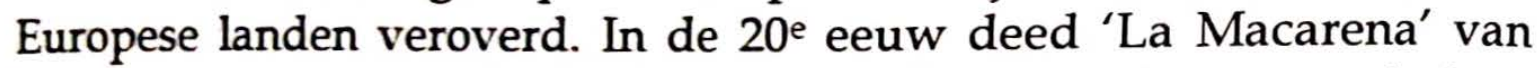
Los del Río zijn intrede in de Nederlandse taal (Spaanse solodans waarbij men op een eenvoudig maar sterk ritme pasjes op de plaats makt), en in de $21^{\mathrm{e}}$ eeuw hebben we de Ketchupdans (Ewoud Sanders 2003: 43):

"In tienduizenden jonge gezinnen is hij in 2002 talloze malen gedanst, de Ketchupdans. Je leerde hem door te kijken naar de videoclip van de zusjes Pilar, Lola en Lucía, dochters van de Spaanse flamencogitarist Tomate. Vanwege Tomate heette het nummer 'Las Ketchup' of'The Ketchup Song' (en in het Spaans Aserejé). Het liedje gaat over een zekere Diego, die een Engelse hit probeert na te zingen, maar niet verder komt dan wat onzinteksten. Een citaat uit het Limburgs Nieuwsblad van 24 augustus 2002: Na de pizzadans is het tijd voor de Ketchupdans. De absolute nazomerhit is geboren."

De flamenco blijft in de $21^{\mathrm{e}}$ eeuw vreemde woorden leveren zoals duende en cajón. Onlangs werd de flamenco door de Unesco tevens tot 
Werelderfgoed verklaard. In deze stereotype sfeer van feesten en dansen mogen de vreemde woorden botellon en mosquito niet ontbreken. De Dikke Van Dale geeft de volgende betekenissen:

- botellon (2009): 'bijeenkomst van jongeren op een openbare plaats, vaak georganiseerd via een sociaal netwerk, waarbij gedanst en gefeest wordt en alcoholische dranken worden geconsumeerd die de bezoekers in grote flessen meebrengen'. Een voorbeeld uit de Vlaamse krant Het Nieuwsblad van $19 \quad 2010$ [http://www.nieuwsblad.be/article/detail.aspx?articleid =DMF20100519_021]:

"Antwerpen ongerust over 'megadrinkpartij'. Op de sociale netwerksite Facebook hebben meer dan 800 mensen zich al ingeschreven voor een grote drinkpartij in juli in Antwerpen. Bij een gelijkaardige bijeenkomst in het Franse Nantes kwamen vorige week nog duizenden mensen opdagen en viel een dode. De stad Antwerpen bekijkt of er moet ingegrepen worden. De bijeenkomst, die de naam 'Massa Boozefestijn' kreeg, gaat door op 8 juli op het Theaterplein. Deelnemers moeten hun eigen drank meebrengen.'In navolging van onze kameraden in Frankrijk, Nederland, UK, Spanje en zelfs Gent vinden we dat ditmaal Antwerpen aan de beurt moet komen voor een massale meeting waarin vriendschap en alcohol de hoofdrol spelen', klinkt het op de Facebookpagina. Het fenomeen komt overgewaaid uit Spanje. De zogenaamde 'botellones' zijn daar al jaren bijzonder populair. In juni vorig jaar werd al een eerste Vlaamse versie georganiseerd op het Gentse Sint-Pietersplein."

- mosquito (2009). Dit is een type leenwoord met toegevoegde betekenis: 'apparaatje dat een irritant piepgeluid voortbrengt, bevestigd bij hangplekken om hangjongeren te verdrijven'. In het Nederlands bestond het woord muskiet/mosquito al met de betekenis van 
'tropische steekmug'. In een artikel in het NRC Handelsblad staat een goed voorbeeld [http://www.nrc.nl/handelsblad/van/2009/oktober/09 / rotterdam-wil-mosquito-houden-11794778]:

Rotterdam wil mosquito houden. Rotterdam, 9 okt. 2009 - Rotterdam houdt vast aan de mosquito, een apparaat dat een voor jongeren irritante pieptoon produceert. Het stadsbestuur gaat wel onderzoeken of de 37 zoemkastjes in de stad voldoen aan de eisen van de nieuwe Algemene Plaatselijke Verordening. "Ik ben niet trots op dit ding, maar het is een middel om de jeugdoverlast tegen te gaan", zei burgemeester Aboutaleb gisteren in de raadszaal. Minister Ter Horst (Binnenlandse Zaken, PvdA) zei begin dit jaar dat de inzet van mosquito's door gemeenten een brevet van onvermogen is.

Op een heel ander terrein, in het semantisch veld van de kunst, wordt het schilderij Guernica van Picasso vermeld. Andere woorden binnen hetzelfde semantische veld zijn: plateresco en muralisme. In de $20^{e}$ eeuw vinden we redelijk veel uitdrukkingen en tussenwerpsels die uit het Spaans afkomstig zijn, zoals mañana (in de uitdrukking 'niet mañana, maar nu'), nada, loco, hasta la vista, Madre de Dios, cosas de España. $\mathrm{Nu}$, in de $21^{\mathrm{e}}$ eeuw, vinden we de volgende uitdrukkingen/tussenwerpsels: adios (2012), coño (2008) [(jongerentaal) schoft], qué (2012), caramba (2005). Het woord coño is overgenomen uit Zuid-Amerika in de betekenis van 'schurk, smeerlap'. Volgens het woordenboek van de Koninklijke Spaanse Academie DRAE wordt het in Venezuela pejoratief gebruikt om 'kerel' mee aan te duiden (DRAE 2014).

Tevens heeft de rijkdom van de fauna van Zuid-Amerika sporen achtergelaten in de Nederlandse taal: agouta, almiqui, hoatzin, paca, caracara, dogo argentino. En van het Schiereiland de uitgestorven Pyrenese steenbok: bucardo.

Het feit dat de Nederlandse Antillen zich nabij Spaanstalige landen bevinden die drugs produceren, zoals Colombia en Bolivia, 
zorgt ervoor dat in de Nederlandse taal Spaanse woorden als bolita en basuco (acroniem van 'base sucia de coca' in Colombia, Venezuela, etc.) worden ingevoerd. Het vliegveld van Schiphol speelt een belangrijke rol met de arrestatie van personen die drugs in bolletjesvorm vervoeren, zoals Ewoud Sanders opmerkt (2009: 40):

"Hoe het ook zij, sinds 2002 wordt een half-Spaans synoniem gebruikt, namelijk bolitaslikker. Bolita is Spaans voor 'bolletje'. In Curaçao, waar veel bolletjesslikkers vandaan komen en waar onder meer Spaans en Nederlands wordt gesproken, worden zij bolitaslikkers genoemd, vandaar. De enorme ophef over het vrijlaten van gearresteerde bolletjesslikkers op Schiphol, vanwege onvoldoende cellencapaciteit, leidde in 2002 tot allerlei gelegenheidssamenstellingen, zoals bolitabeleid, bolletjesaffaire, bolletjesdode, bolletjeslepel, bolletjesoperette, bolletjesproblematiek, bolletjesprop, bolletjessysteem, bolletjesolucht, bolletjeswet enzovoort.

Met betrekking tot het semantisch veld van religie zien we de overname van twee katholieke termen. Beide vreemde woorden komen uit Spanje: camino, breviatuur van de Camino de Santiago ('bedevaarttocht naar Santiago de Compostella, pelgrimspad') en paso, dat naar de passietaferelen van de Heilige Week verwijst: 'beeldengroep die een gebeurtenis uit de passie voorstelt en die in de Stille Week voor Pasen in processie meegedragen wordt.' (Van Dale 2013). Uit Centraal-Amerika hebben we santeria <esp. santería.

Ook de Spaanse architectuur en bouw dragen een aanzienlijk aantal woorden aan gedurende de $21^{\mathrm{e}}$ eeuw: alfiz, alicatado, artesonado, mocarabe, parador, plaza, plaza mayor. Veel van deze woorden hebben een Arabische herkomst.

In de $21^{\mathrm{e}}$ eeuw heeft het grootste werk uit de Spaanse literatuur nog altijd invloed met de meerwoordvertaling (Sijs 2005: 509) el caballero de la triste figura. Dit wordt naar het Nederlands vertaald als ridder van de droevige figuur.

Binnen het semantisch veld van sport is in de Dikke Van Dale de uitdrukking un momento dado opgenomen: "geëxtraheerd uit Spaans en un momento dado (<nl. op een gegeven moment), een kernachtige uitspraak van voetballer Johan Cruijff op basis van een Nederlandse gedachte" (Van Dale 2013). In 2004 werd er een documentaire over 
Johan Cruijff opgenomen met de titel 'En un momento dado', die de Spaanse uitdrukking in Nederland populair heeft gemaakt (Sijs 2010 . vii).

\section{CONCLUSIES}

In absolute termen gesproken is het semantisch veld met het grootste aantal vreemde woorden dat aan de Nederlandse taal is toegeschreven ( $21,25 \%$ van het totaal) dat van dranken/eten, zoals de volgende grafiek aantoont:

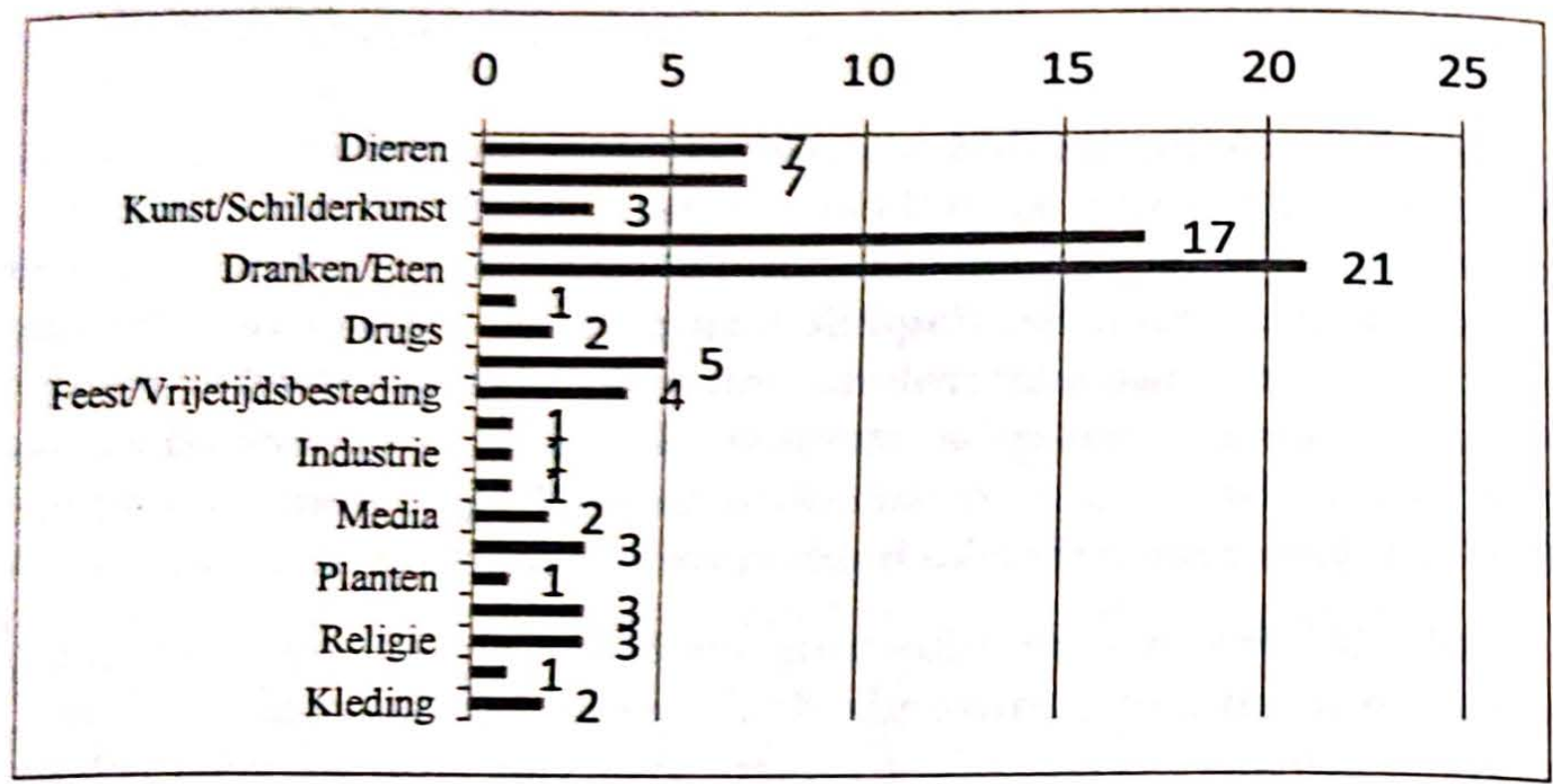

De laatste jaren is de internationale waardering voor het mediterrane dieet, met de Spaanse keuken als prototypische voorstelling, toegenomen. Op de tweede plaats staat het semantisch veld van dans/muziek, met 17 vreemde woorden $(20 \%$ van het totaal). Dit is toe te schrijven aan de invloed van de LatijnsAmerikaanse muziek, die de eerste plaatsen van de Europese hitparades bezet. Daarnaast is de flamenco als Werelderfgoed aangewezen. In het Nederlands is een breed scala aan semantische velden opgenomen, zoals uit de grafiek valt af te lezen. Hierdoor kan 
bevestigd worden dat het Spaans op verschillende aspecten van het leven invloed heeft. Op de vijfde plaats, met 5 woorden, vinden we het semantisch veld

van uitdrukkingen/tussenwerpsels/scheldwoorden. Dit wijst op nauw contact tussen beide talen, aangezien dit soort vocabulaire niet technisch is.

Analyseren we hoe het Spaanse vocabulaire zich in de Nederlandse spelling en grammatica heeft geïntegreerd, dan blijkt dat van de 85 woorden er 70 ongewijzigd overgenomen zijn, met behoud van de Spaanse spelling en fonetica: agouta, alfiz, alicatado, artesonado, basuco, batucada, bombo, bucardo, burrito, cajón (het accent wordt behouden), camino, caracara, caramba, cava, cenote, ceviche, chompa, chullo (de $\mathrm{Ml}$ / wordt wel uitgesproken), churros, charango, conchita, coño, crianza, cumbia, dogo argentino, duende, pipa, EFE, ELDR, encierro, epazote, escabeche, fajita, garbanzo, GT, Guernica, hoatzin, ketchupdans, manchego, maquiladora, membrillo, mestizo, mojito, mosquito, paca, paso, pasco, pata negra, pandeiro, parador, piñata, plateresco, plaza, plaza mayor, PPE-DE, PSE, qué, quesadilla, ranchera, reserva, roner, son, tanguero, tempranillo, tiple, tres, TVE, un momento dado, vihuela.

In de tweede plaats zijn de accenttekens van de volgende etyma verdwenen: adios, almiqui, botellon (de /ll/ wordt niet uitgesproken), guanabana, santeria (maar legt in de uitspraak de klemtoon op ía). Vervolgens zijn twee termen tegelijk op twee mogelijke manieren overgenomen; als zodanig in het Spaans en met de Nederlandse vertaling: bolita/bolletje, el caballero de la triste figura/ridder van de droevige figuur. In de vierde plaats zijn aan de Nederlandse spelling aangepast: muralisme <sp. muralismo, nacho's <sp. nachos, piperade <sp. piperrada, tapa(sbar) (vorming van een samenstelling) <sp. bar de tapas, ketchupdans <sp. Baile de las Ketchup. Als laatste wordt bij het woord serranoham <sp. jamón serrano, het tweede deel van de samenstelling vertaald, jamón door ham, maar niet het eerste deel, serrano. Daar het recente vreemde woorden betreft, is het logisch dat de meeste Spaanse termen, voor nu, niet naar het Nederlands worden vertaald, maar we zullen zien wat er op middellange tot lange termijn gebeurt. 
Van het lexicale corpus bestaande uit 85 vreemde woorden, zijn 43 woorden afkomstig van het Spaans van Zuid-Amerika (voor zover mogelijk zijn deze gerangschikt met vermelding van het betreffende land) en 42 van het Spaans van Spanje:

- Spanje (42): adios, alfiz, alicatado, artesonado, botellon, bucardo, camino, cava, churros, conchita, crianza, duende, el caballero de la triste figura, EFE, ELDR, encierro, escabeche, garbanzo, Guernica, ketchupdans, manchego, membrillo, mestizo, mocarabe, mosquito, paseo, paso, pata negra, parador, piperade, plateresco, plaza mayor, PPE-DE, PSE, reserva, roner, serranoham, tapa(sbar), tempranillo, TVE, un momento dado, vihuela, qué.

- Zuid-Amerika/Centraal-Amerika (43): agouta [eiland Hispaniola, Dominicaanse Republiek en Haïti], almiqui [Cuba], basuco [Colombia, Ecuador, Venezuela], batucada [Brazilië], bolita [Curaçao], bombo [Argentinië], bombonella [Zuid-Amerika, Caraïben], burrito [Mexico], cajón [Argentinië], caracara [Noorden van Zuid-Amerika en Centraal-Amerika], caramba [Mexico], cenote [Mexico], ceviche [Noorden van Zuid-Amerika en CentraalAmerika], chompa [Noorden van Zuid-Amerika en Centraal-Amerika], chullo [Peru], charango [Peru], coño [Venezuela], cumbia [Colombia], dogo argentino [Argentinië], epazote [Mexico], fajita [Mexico], GT [Mexico], guaganco [Cuba], guanabana [Cuba, Antillen], hoatzin [Mexico], maquiladora [Mexico, Guatemala, Honduras], melodeon [Colombia], mojito [Cuba], muralisme [Mexico], nacho's [Mexico], paca [In bijna heel Amerika], pandeiro [Brazilië, Zuid-Amerika], plaza [Zuid-Amerika, via het Engels 'plein van een winkelcentrum'], piñata [Mexico], pipa [Zuid-Amerika], quesadilla [Mexico], ranchera [Mexico], santeria [Cuba, Venezuela], son [Cuba], tanguero [Argentinië], tiple [Colombia], tres 2 [Cuba].

Bij vergelijking van de gegevens van de Spaanse vreemde woorden afkomstig van Spanje met die van Amerika, dan bedragen 
beide percentages ongeveer $50 \%$. Dit percentage van het Amerikaanse Spaans is zeer hoog gezien de afstand ten opzichte van het Spaans van Spanje, dat zich op het Europese continent bevindt. Van de vreemde woorden die van het Amerikaanse Spaans zijn afgeleid, blijkt dat een vierde uit Mexico komt.

Aan de hand van de volgende grafiek, zijn er verschillende punten te observeren.

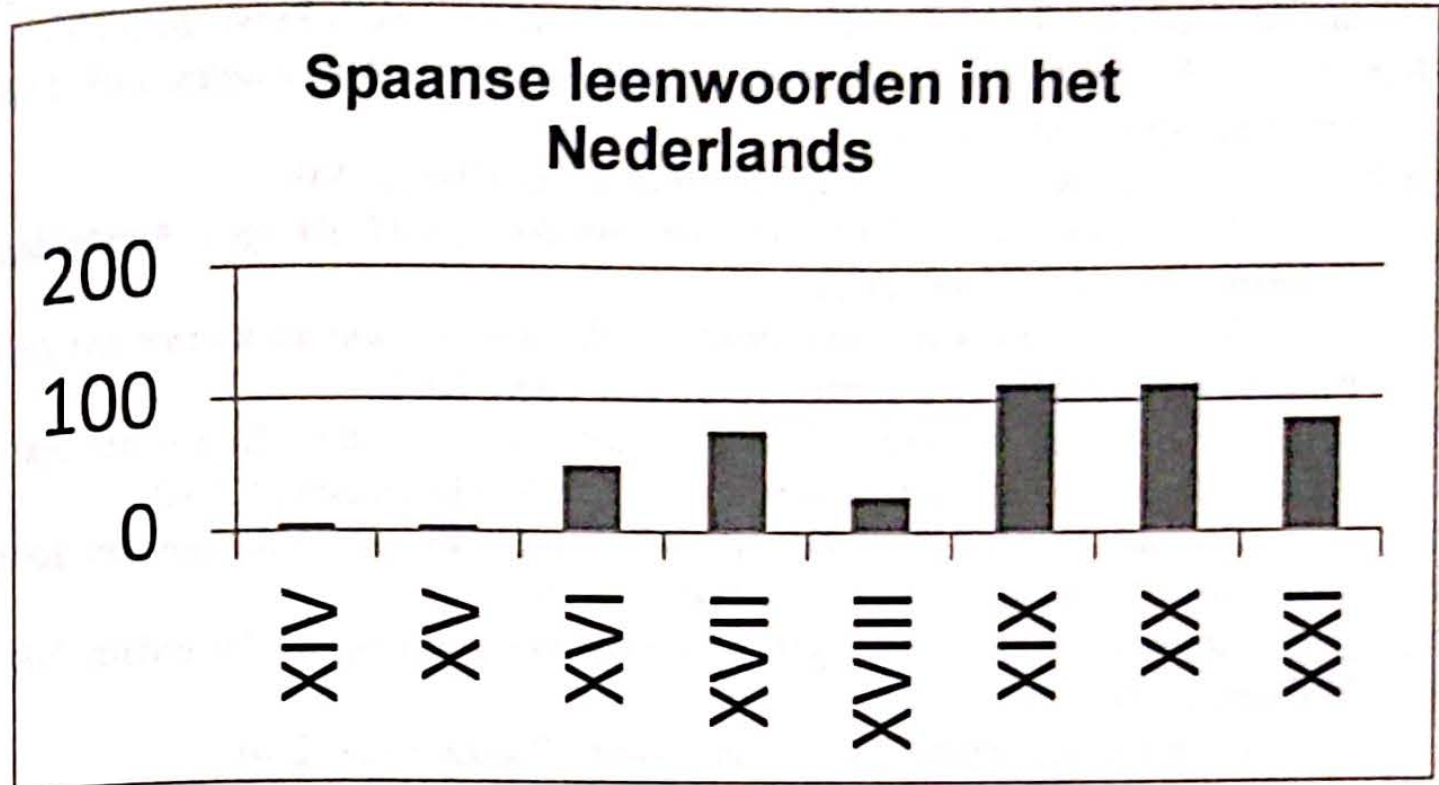

De $14^{e}$ en $15^{e}$ eeuw vormen het begin met een klein aantal leenwoorden, respectievelijk 5 en 4. Zodra de Lage Landen deel uitmaken van de Spaanse kroon begint de opkomst van de invloed van woorden met een geleidelijke stijging, 50 leenwoorden in de $16^{e}$

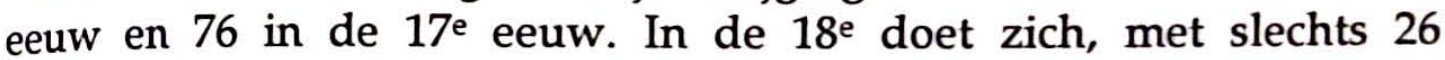
leenwoorden, een afname voor, die samenvalt met de onafhankelijkheid van de Nederlanden van de Spaanse kroon. En vanaf de $19^{e}$ eeuw, met de opkomst van het nationalisme, begint er een opvallende stijging, waarna het aantal ongeveer gelijk blijft, 112 leenwoorden in de $19^{\mathrm{e}}$ eeuw en 111 in de $20^{\mathrm{e}}$ eeuw. Al deze gegevens zijn zoals verwacht. Spectaculair is dat van de dertien jaar van de $21^{\mathrm{e}}$ eeuw die zijn onderzocht, er reeds 85 vreemde woorden zijn opgenomen, waarvan, zowel in de $20^{e}$ als in de $21^{e}$ eeuw, het 
semantisch veld met de meeste woorden die zijn toegeschreven dat eten en dranken is, gevolgd door het semantisch veld van dans en muziek.

\section{BIBLIOGRAFIE}

Debrabandere, F.; MARLIES, P.; QuACK, A. (eds.), Etymologisch woordenboek van het Nederlands, Amsterdam, Amsterdam University Press, 2003-2009.

Kolsteren A.; SANDERS, E., Vreemde Woorden. Prisma Woordenboek, 24ste druk, Houten, Spectrum, 2008.

SANDERS, E., Allemaal woorden, Amsterdam, Prometheus, 2005.

De taal van het jaar 2000: Nieutve woorden en uitdrukkingen, Amsterdam / Antwerpen, L.J. Veen, 2001.

De taal van het jaar. Tweehonderdvijftig woorden die het aanzien van 2001 bepaalden, Amsterdam / Antwerpen, L.J. Veen, 2002.

De taal van het jaar: de nieuwe woorden en uitdrukkingen van 2002, Amsterdam / Rotterdam, Prometheus / NRC Handelsblad, 2003.

De taal van het jaar. De nieuwe woorden en uitdrukkingen van 2003, Amsterdam / Rotterdam, Prometheus, 2004.

Van asotaks tot zedenpleger. Tien jaar nieuwe woorden, Rotterdam, NRC Boeken, 2009.

Woorden met een oerhaal, Amsterdam, Prometheus, 2004.

SIS, N. (VAN DER), Chronologisch Woordenboek, Amsterdam, L.J. Veen, 2001. 1998.

Geleend en uitgeleend, Amsterdam/Antwerpen, Uitgeverij Contact,

Leenwoordenboek: de invloed van andere talen op het Nederlands, Den Haag, Sdu; Standaard, 1996.

Groot Leenwoordenboek. De invloed van andere talen op het Nederlands, Utrecht/Antwerpen, Van Dale, 2005.

Klein uitleenwoordenboek, Utrecht, Sdu Uitgevers, 2006.

Nederlandse woorden wereldwijd, Den Haag, Sdu Uitgevers, 2010.

VAN DALE, Cultuurtoeristische Van Dale. Woordenboekgids voor de cultuurtoerist, Utrecht/Antwerpen, Van Dale, 2007.

Elektronisch groot woordenboek van de Nederlandse taal. Dikke Van Dale.

Versie 14.9., Utrecht/Antwerpen, Van Dale, 2013.

Groot woordenboek der Nederlandse Taal op CD-Rom. Plus versie 1.0., Utrecht/Antwerpen, Van Dale 2000.

Groot Woordenboek der Nederlandse Taal op CD-ROM. Versie 14.0.

Utrecht/Antwerpen, Van Dale, 2005. 

Internet

http://www.etymologiebank.nl

http://www.vandale.nl

http://www.onzetaal.nl

http://www.nieuwsblad.be

http://www.nrc.nl

http://www.rae.es/rae.html 